\title{
Article
}

\section{Effects of Processing Treatments on the Chemical Composition of Tiger Nut (Cyperus esculentus) Milk Products}

\author{
Hafiz Abubakar, Muhammad Atiku, Adamu Alhassan and Amina Sa'id * \\ Department of Biochemistry, Faculty of Basic Medical Sciences Bayero University Kano, PMB 3011 Kano State, \\ Nigeria \\ * Correspondence: aminasaid02@yahoo.com; Tel.: +2348065270866
}

Abstract: Tiger nut (Cyperus esculentus) is an edible perennial grass-like plant that has long been recognized for its health benefits as it is rich in fiber, protein, vitamins, minerals and natural sugars. It can be eaten raw, roasted or made into a refreshing milk which is very nutritive and healthy for consumption. There were several efforts to mass-produce the locally prepared tiger nut milk in our locality, but the fact that it has a shorter shelf-life, brings about a hindrance. The main objective of the present study is to unveil the cause for the easily spoilage of tiger nut milk and device ways to promote its production using different treatments. Tiger nut milk products were prepared using different methods; water soaked tiger nut milk (WSTM), toasted tiger nut milk (TTM), methanol soaked tiger nut milk (MSTM), and the pasteurised tiger nut milk (PTM). Each of these milk proucts prepared was divided into two portions; the first portion is treated with an antibiotic preservative, Nisin and the second portion was left untreated. The two portions were further divided into two; one stored at refrigerating temperature and the other at room temperature, making four different treatments per mixture and a total of 16 samples. These samples were subjected to proximate analysis; protein, fat, moisture, ash and carbohydrate. The chemical composition of the samples was significantly $(\mathrm{P}<0.05)$ affected by processing treatment. All the samples had high moisture content, and a considerable amount of fat. The preservative treated samples that received pasteurized treatment were found to stay more than a week with fair quality. Findings from the study shows that the chemical characteristics of the various milk products were significantly affected by the different processing treatments.

Keywords: Nisin, water soaked tiger nut milk (WSTM), toasted tiger nut milk (TTM), methanol soaked tiger nut milk (MSTM), and the pasteurised tiger nut milk (PTM)

\section{Introduction}

Milk is an important source of nutrients and serve as a source of food for infants, growing children and adults [1]. It is the primary source of nutrients for infant mammals before they are able to digest other types of food. The high cost of milk in developing countries has led to the development of alternative source of milk from plant materials [2]. A protein-rich drink can be produced from locally available plant foods at an affordable price in place of animal protein which is scarce and expensive, and could play an important role to reduce protein malnutrition. 
Plant milk has been consumed for centuries in various cultures, both as a regular drink (such as the Spanish horchata) and as a substitute for dairy milk. The most popular varieties are soy milk, almond milk, rice milk and coconut milk. Their protein content varies. It contains no lactose or cholesterol, and is usually sold with added calcium and vitamins, especially $\mathrm{B}_{12}$. Only soybean has been extensively investigated while other oil seeds and tubers such as tigernut, have not been studied comprehensively. Little research attention has been given to bambaranut [3], baobab [1], peanut [4], melon seed [5] and tiger nut milk [6] as sources of vegetable milk.

Tiger nut, an under-utilized crop, was reported to be high in dietary fibre content, which could be effective in the treatment and prevention of many diseases including colon cancer, coronary heart diseases, obesity, diabetes and gastrointestinal diseases [7]. It has 5.8\% moisture, rich in protein (7\%) [8] and carbohydrates such as reducing sugar (7.4\%), soluble polysaccharide (7.4\%) and starch $(86.4 \%)$ [9]. Tiger nut is also rich in mineral elements such as sodium, calcium, potassium, magnesium, zinc and traces of copper [10]. According to Ojobe and Tempo [11], the protein in tiger nut is of high biological value considering the many essential amino acids it contains. These amino acids are higher than those proposed in the standard by the FAO/WHO $[12,13]$ and satisfy amino acid need of adults [14].

Tiger nuts are a rich source of nourishment, and remain a significant source of food for both the poor and the wealthy throughout Northwest Africa. They are a good sources of oleic acid (a monounsaturated fat also found in olive oil and avocado), and which is associated with increased HDL (good) cholesterol levels.

Tiger nuts can be processed into varieties of milk products like water soaked tiger nut milk, toasted tiger nut milk, methanol soaked tiger nut milk and the pasteurised tiger nut milk. Tiger nut milk can be used by special people having milk allergies such as galactosemia and lactose intolerance.

The tiger nut milk is a stimulating vegetable drink prepared mainly with tiger nut, water and sugar. It's milk can serve as a good alternative to cow milk with a natural sweetened taste [15].The milk is said to be rich in minerals, like phosphorus, calcium and magnesium, iron and in vitamin C and $\mathrm{E}$ which are vital for body growth and development. It does not contain lactose or gluten; this makes it a suitable choice for people who are not able to tolerate gluten (celiac patients) and also for the lactose-intolerant who stay away from cow milk and other dairy products [16].

Due to its content of some digestive enzymes like catalase, lipase, and amylase, tiger nut milk could be recommended for people with problems of digestion, flatulence and diarrhea [17].

The ability to keep the milk for a long period of time has been a major drawback as it easily got spoiled. The aim of the research is therefore, to determine the effect of various processing treatments on the chemical composition of the tigernut milk.

\section{Materials and Methods}

Fresh tigernuts (Cyperus esculentus) and spices were obtained from Rimi market in Kano State, Nigeria. The tigernut was authenticated in the Department of Plant Biology, Bayero University Kano with the accession number BUKHAN 0367 by Baha'uddeen Sa'id Adam. The spices used 
77 include ginger (Zingiber officinate) and cloves (Eugenia coryphée). The chemical preservative used was

78 Nisin, then vanilla flavor and sugar.

\section{$79 \quad$ Preparation of Tigernut Milk}

80 Fresh tubers of tigernut were sorted, washed and rinsed with distilled water then used to 81 produce different milk products as follows:

Water Soaked Tigernut Milk (WSTM):

83

90• Water soaked tigernut milk + Preservative (2g to $2 \mathrm{~L}$ of the filtrate) at room temperature (WSTM + 91 РRT).

92 - Water soaked tigernut milk stored at refrigeration temperature (WSTMRef.T).

93• Water soaked tigernut milk stored at room temperature (WSTMRT).

94

In this portion, the fresh tigernut was directly soaked in water for 2hours, blended, filtered, sugar and flavor were added. The filtrate was then divided into two portions; one treated with Nisin preservative ( $2 \mathrm{~g}$ to $2 \mathrm{~L}$ of the filtrate) and the other portion was not treated with any preservative. Each of these two portions was again divided into two; one stored at refrigerating temperature and the other one at room temperature, making four different treatments:

Water soaked tigernut milk + Preservative $(2 \mathrm{~g}$ to $2 \mathrm{~L}$ of the filtrate) at refrigeration temperature (WSTM+PRef.T).

\section{Toasted Tigernut Milk (TTM):}

The fresh tigernut was toasted at $110 \pm 5^{\circ} \mathrm{C}$ for 30 minutes in an open pan. It was then blended and mixed; and divided into four portions as done for the first portion.

Toasted tigernut milk + Preservative $(2 \mathrm{~g}$ to $2 \mathrm{~L}$ of the filtrate) at refrigeration temperature (TTM+ PRef.T).

Toasted tigernut milk + Preservative (2g to $2 \mathrm{~L}$ of the filtrate) at room temperature (TTM + PRT).

Toasted tigernut milk stored at refrigeration temperature (TTMRef.T).

Toasted tigernut milk stored at room temperature (TTMRT).

\section{Methanol Soaked Tigernut Milk (MSTM)}

In this portion, the tigernut was partly ground and soaked in methanol solution for an hour. It was then removed, dried (so as to allow the methanol to evaporate) and soaked in water (water was changed three times). It was also divided into four portions as above:

- Methanol soaked tigernut milk + Preservative (2g to $2 \mathrm{~L}$ of the filtrate) at refrigeration tempe rature (MSTM + PRef.T).

- Methanol soaked tigernut milk + Preservative (2g to $2 \mathrm{~L}$ of the filtrate) at room temperature (MSTM + PRT).

- Methanol soaked tigernut milk stored at refrigeration temperature (MSTM Ref.T).

- Methanol soaked tigernut milk stored at room temperature (MSTMRT). 
114

\section{5}

116

117

118

119•

$120+$ Pref.T).

121. Pasteurized tigernut milk + Preservative ( $2 \mathrm{~g}$ to $2 \mathrm{~L}$ of the filtrate) at room temperature (PTM + PRT).

122• Pasteurized tigernut milk stored at refrigeration temperature (PTM Ref.T).

123. Pasteurized tigernut milk stored at room temperature (PTMRT).

124 The proximate composition and $\mathrm{pH}$ of each sample were analysed at an interval of 4 days.

125

126

127

128

129

130

131

132

133

134

135

136

137

138

139

140

141

142

143

144

145

146

147

\section{Chemical Analysis:}

Moisture, ash, fat, protein, carbohydrate by difference and $\mathrm{pH}$ were determined according to standard methods [18].

\section{Statistical Analysis:}

The analyses were performed in triplicates. The mean values and standard deviation were calculated (mean \pm SD) using SPSS package16.

\section{Results}

\subsection{Effect of Processing on the Chemical Characteristics of Tigernut Milk Products:}

The effects of processing on the chemical characteristics of tigernut milk products are presented on Tables 1-5.

All the samples in table 1 had high moisture content, with TTM+PRT having the highest percentage. Also, TTM+PRefT and PTM+PRefT were significantly different from other samples in terms of their carbohydrate contents. While WSTMRefT and MSTMRT had the highest percentage of protein.

No significant difference existed in almost all the samples in the various parameters after eight (8) days of production. Only PTM+PRT had high percentage of protein (10.7\%).

Twelve (12) days after production, all samples had high percentages for moisture content ranging from $71-82 \%$. WSTMreft and PTM+PRT showed significant difference in their protein contents (10.9\%).

In table 4, the percentage fat content of PTMRefT was statistically significant; and WSTMRT and

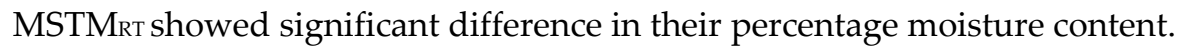

Significant difference existed between WSTM+PRT and PTM+PRT and other samples in terms of percentage fat content. While WSTM+Рвт and WSTMRт samples had highest moisture content after twenty (20) days of production. 
148 Table 1. Proximate composition of tigernut milk products obtained from various processing 149 treatments after four (4) days of production.

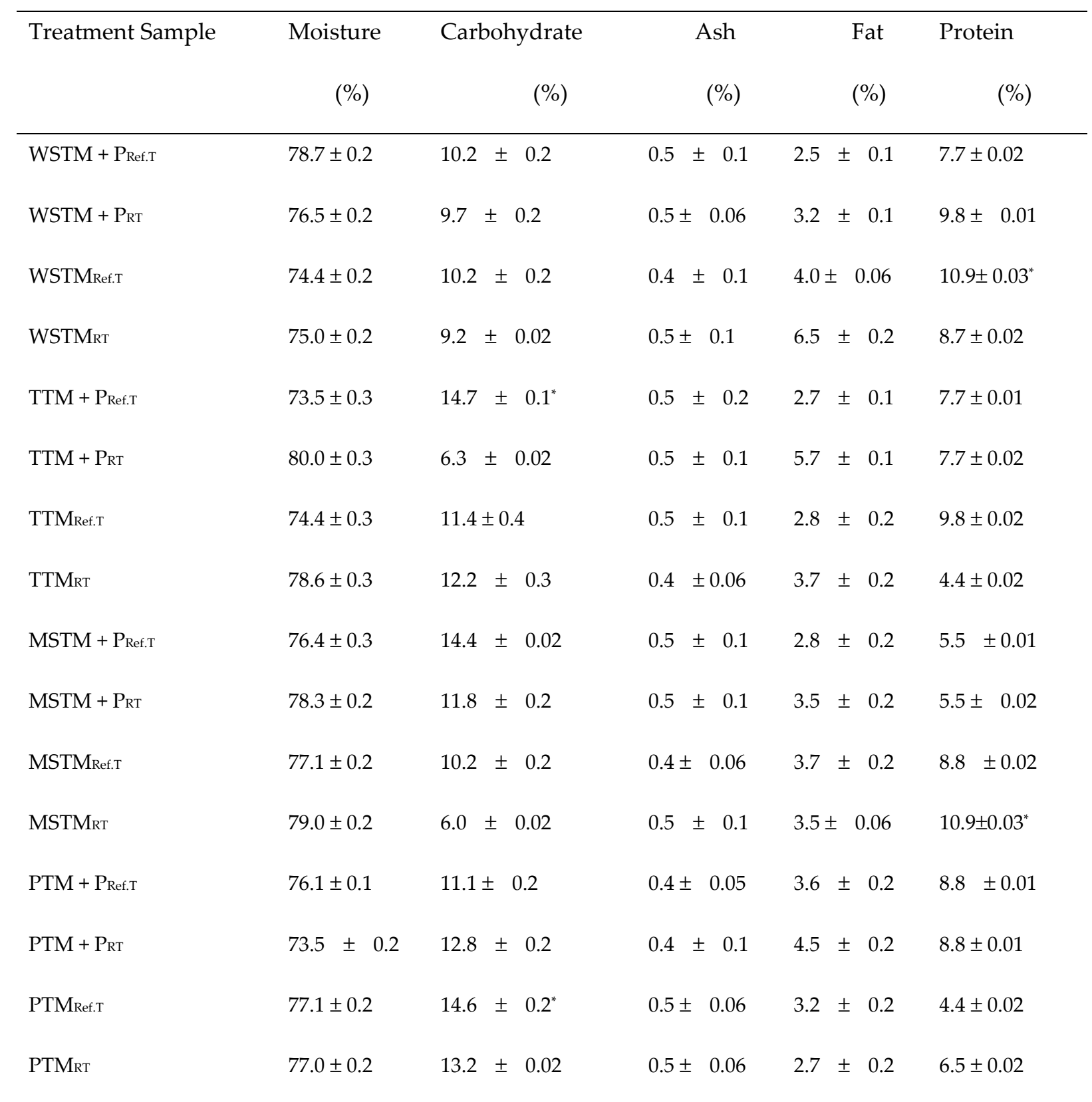

Values are means \pm SD of triplicate determinations

151 Values in same columns bearing the superscript ${ }^{*}$ ) are significant at $\mathrm{P}<0.05$

152 Key for tables 1-6:

153 WSTM+ Pref.T $=$ Water soaked tigernut milk + preservative (at refrigerating temperature)

$154 \mathrm{WSTM}+\mathrm{P}_{\mathrm{RT}}=$ Water soaked tigernut milk + preservative (at room temperature),

155 WSTM Ref.T = Water soaked tigernut milk (at refrigerating temperature), 
157 TTM = Toasted tigernut milk,

158 MSTM = Methanol soaked tigernut milk and

$159 \quad \mathrm{PTM}=$ Pasteurised tigernut milk.

160 Table 2. Proximate composition of tigernut milk products obtained from various processing 161 treatments after eight (8) days of production.

\begin{tabular}{|c|c|c|c|c|c|}
\hline Treatment Sample & $\begin{array}{r}\text { Moisture } \\
\text { (\%) }\end{array}$ & $\begin{array}{r}\text { Carbohydrate } \\
(\%)\end{array}$ & $\begin{array}{l}\text { Ash } \\
(\%)\end{array}$ & $\begin{array}{l}\text { Fat } \\
(\%)\end{array}$ & $\begin{array}{l}\text { Protein } \\
\qquad(\%)\end{array}$ \\
\hline WSTM + PRef.T & $80.7 \pm 0.2$ & $7.6 \pm 0.2$ & $0.5 \pm 0.1$ & $3.5 \pm 0.1$ & $7.6 \pm 0.02$ \\
\hline $\mathrm{WSTM}+\mathrm{P}_{\mathrm{RT}}$ & $81.7 \pm 0.1$ & $9.0 \pm 0.2$ & $0.5 \pm 0.05$ & $3.2 \pm 0.2$ & $5.5 \pm 0.02$ \\
\hline WSTBRef.T & $84.1 \pm 0.4$ & $7.3 \pm 0.01$ & $0.5 \pm 0.05$ & $2.7 \pm 0.2$ & $5.5 \pm 0.01$ \\
\hline WSTMRT & $83.0 \pm 0.2$ & $3.7 \pm 0.02$ & $0.5 \pm 0.05$ & $2.7 \pm 0.1$ & $9.8 \pm 0.02$ \\
\hline TTM + PRef.T & $80.0 \pm 0.3$ & $8.2 \pm 0.02$ & $0.5 \pm 0.1$ & $2.5 \pm 0.2$ & $8.8 \pm 0.02$ \\
\hline $\mathrm{TTM}+\mathrm{P}_{\mathrm{RT}}$ & $79.2 \pm 0.2$ & $13.4 \pm 0.02$ & $0.5 \pm 0.1$ & $2.3 \pm 0.2$ & $4.4 \pm 0.02$ \\
\hline TTMRef.T & $78.2 \pm 0.2$ & $14.0 \pm 0.2$ & $0.5 \pm 0.05$ & $2.6 \pm 0.1$ & $4.4 \pm 0.02$ \\
\hline TTMRT & $83.4 \pm 0.1$ & $4.8 \pm 0.02$ & $0.5 \pm 0.05$ & $2.5 \pm 0.2$ & $8.8 \pm 0.02$ \\
\hline MSTM + PRef.T & $79.0 \pm 0.2$ & $11.5 \pm 0.03$ & $0.5 \pm 0.05$ & $3.4 \pm 0.2$ & $5.5 \pm 0.01$ \\
\hline MSTM + PRT & $82.2 \pm 0.2$ & $3.9 \pm 0.02$ & $0.6 \pm 0.05$ & $3.5 \pm 0.2$ & $9.8 \pm 0.02$ \\
\hline MSTMRef.T & $79.3 \pm 0.1$ & $7.3 \pm 0.02$ & $0.5 \pm 0.05$ & $4.2 \pm 0.2$ & $8.8 \pm 0.02$ \\
\hline MSTMRT & $85.3 \pm 0.2$ & $5.0 \pm 0.03$ & $0.5 \pm 0.05$ & $2.5 \pm 0.1$ & $6.5 \pm 0.02$ \\
\hline PTM + Pref.T & $79.0 \pm 0.2$ & $10.9 \pm 0.03$ & $0.5 \pm 0.1$ & $3.0 \pm 0.2$ & $6.5 \pm 0.02$ \\
\hline $\mathrm{PTM}+\mathrm{P}_{\mathrm{RT}}$ & $80.3 \pm 0.1$ & $4.9 \pm 0.02$ & $0.5 \pm 0.05$ & $3.4 \pm 0.2$ & $10.7 \pm 0.02^{*}$ \\
\hline PTMRef.T & $78.0 \pm 0.2$ & $9.9 \pm 0.02$ & $0.6 \pm 0.2$ & $2.8 \pm 0.1$ & $8.7 \pm 0.02$ \\
\hline PTMRT & $79.4 \pm 0.2$ & $9.7 \pm 0.02$ & $0.5 \pm 0.1$ & $2.7 \pm 0.2$ & $7.7 \pm 0.02$ \\
\hline
\end{tabular}

162 Values are means \pm SD of triplicate determination. Values in same columns bearing the superscript $\left({ }^{*}\right)$ are

163 significant at $\mathrm{P}<0.05$ 
166 Table 3. Proximate composition of tigernut milk products obtained from various processing 167 treatments after twelve (12) days of production.

\begin{tabular}{|c|c|c|c|c|c|}
\hline Treatment Sample & $\begin{array}{r}\text { Moisture } \\
\text { (\%) }\end{array}$ & $\begin{array}{r}\text { Carbohydrate } \\
(\%)\end{array}$ & $\begin{array}{l}\text { Ash } \\
(\%)\end{array}$ & $\begin{array}{l}\text { Fat } \\
(\%)\end{array}$ & $\begin{array}{l}\text { Protein } \\
\qquad(\%)\end{array}$ \\
\hline WSTM + PRef.T & $74.0 \pm 0.2$ & $14.0 \pm 0.3$ & $0.5 \pm 0.1$ & $3.8 \pm 0.2$ & $7.7 \pm 0.02$ \\
\hline WSTM + PRT & $78.2 \pm 0.2$ & $7.2 \pm 0.2$ & $0.5 \pm 0.05$ & $4.2 \pm 0.3$ & $9.8 \pm 0.02$ \\
\hline WSTMRef.T & $71.0 \pm 0.3$ & $13.5 \pm 0.02$ & $0.5 \pm 0.05$ & $4.0 \pm 0.2$ & $10.9 \pm 0.02^{*}$ \\
\hline WSTMRT & $82.0 \pm 0.2$ & $5.4 \pm 0.03$ & $0.5 \pm 0.1$ & $4.4 \pm 0.2$ & $7.7 \pm 0.02$ \\
\hline TTM + PRef.T & $73.0 \pm 0.2$ & $14.9 \pm 0.02$ & $0.4 \pm 0.05$ & $2.8 \pm 0.1$ & $8.8 \pm 0.02$ \\
\hline $\mathrm{TTM}+\mathrm{P}_{\mathrm{RT}}$ & $80.0 \pm 0.1$ & $6.4 \pm 0.2$ & $0.5 \pm 0.05$ & $3.2 \pm 0.2$ & $9.8 \pm 0.03$ \\
\hline TTMRef.T & $78.0 \pm 0.2$ & $12.5 \pm 0.03$ & $0.5 \pm 0.1$ & $3.0 \pm 0.3$ & $5.5 \pm 0.01$ \\
\hline TTMRT & $81.0 \pm 0.1$ & $7.7 \pm 0.02$ & $0.4 \pm 0.05$ & $3.2 \pm 0.2$ & $7.7 \pm 0.02$ \\
\hline MSTM + Pref.T & $82.0 \pm 0.2$ & $5.0 \pm 0.02$ & $0.5 \pm 0.1$ & $3.6 \pm 0.3$ & $8.8 \pm 0.03$ \\
\hline $\mathrm{MSTM}+\mathrm{P}_{\mathrm{RT}}$ & $80.4 \pm 0.3$ & $7.0 \pm 0.03$ & $0.5 \pm 0.05$ & $3.2 \pm 0.1$ & $8.8 \pm 0.03$ \\
\hline MSTMRef.T & $76.0 \pm 0.2$ & $14.1 \pm 0.02$ & $0.5 \pm 0.05$ & $2.8 \pm 0.2$ & $6.5 \pm 0.02$ \\
\hline MSTMRT & $82.0 \pm 0.2$ & $6.0 \pm 0.1$ & $0.5 \pm 0.1$ & $3.8 \pm 0.2$ & $7.7 \pm 0.01$ \\
\hline PTM + Pref.T & $73.0 \pm 0.1$ & $11.3 \pm 0.2$ & $0.5 \pm 0.1$ & $4.2 \pm 0.2$ & $10.9 \pm 0.02 *$ \\
\hline $\mathrm{PTM}+\mathrm{P}_{\mathrm{RT}}$ & $72.3 \pm 0.2$ & $13.5 \pm 0.02$ & $0.5 \pm 0.05$ & $4.8 \pm 0.02^{*}$ & $8.8 \pm 0.02$ \\
\hline PTMRef.T & $72.0 \pm 0.2$ & $13.5 \pm 0.02$ & $0.5 \pm 0.1$ & $4.0 \pm 0.3$ & $9.8 \pm 0.02$ \\
\hline PTMrT & $72.0 \pm 0.3$ & $13.0 \pm 0.2$ & $0.5 \pm 0.05$ & $4.0 \pm 0.2$ & $9.8 \pm 0.02$ \\
\hline
\end{tabular}

168 Values are means \pm SD of triplicate determinations. Values in same columns bearing the superscript $\left({ }^{*}\right)$ are 169 significant at $\mathrm{P}<0.05$ 
175 Table 4. Proximate composition of tigernut milk products obtained from various processing 176 treatments after sixteen (16) days of production.

\begin{tabular}{|c|c|c|c|c|c|}
\hline Treatment Sample & Moisture & Carbohydrate & Ash & Fat & Protein \\
\hline & $(\%)$ & $(\%)$ & $(\%)$ & $(\%)$ & $(\%)$ \\
\hline WSTM + PRef.T & $78.0 \pm 0.2$ & $7.3 \pm 0.2$ & $0.5 \pm 0.1$ & $3.2 \pm 0.2$ & $10.9 \pm 0.02$ \\
\hline WSTM + PRT & $81.0 \pm 0.1$ & $3.5 \pm 0.2$ & $0.5 \pm 0.05$ & $4.0 \pm 0.2$ & $10.9 \pm 0.02$ \\
\hline WSTMRef.T & $80.0 \pm 0.2$ & $8.3 \pm 0.3$ & $0.5 \pm 0.05$ & $3.5 \pm 0.2$ & $7.7 \pm 0.02$ \\
\hline WSTMRT & $85.0 \pm 0.3^{*}$ & $4.4 \pm 0.02$ & $0.5 \pm 0.1$ & $3.6 \pm 0.2$ & $6.5 \pm 0.02$ \\
\hline TTM + Pref.T & $79.0 \pm 0.2$ & $10.0 \pm 0.2$ & $0.5 \pm 0.1$ & $2.8 \pm 0.2$ & $7.7 \pm 0.01$ \\
\hline $\mathrm{TTM}+\mathrm{P}_{\mathrm{RT}}$ & $79.0 \pm 0.1$ & $8.5 \pm 0.2$ & $0.5 \pm 0.05$ & $3.2 \pm 0.1$ & $8.8 \pm 0.02$ \\
\hline TTMRef.T & $77.0 \pm 0.2$ & $10.7 \pm 0.02$ & $0.5 \pm \quad 0.1$ & $3.0 \pm 0.2$ & $8.8 \pm 0.02$ \\
\hline TTMRT & $81.0 \pm 0.3$ & $9.5 \pm 0.03$ & $0.5 \pm 0.1$ & $3.5 \pm 0.2$ & $5.5 \pm 0.01$ \\
\hline MSTM + PRef.T & $81.0 \pm 0.2$ & $11.5 \pm 0.2$ & $0.5 \pm 0.1$ & $2.5 \pm 0.2$ & $4.4 \pm 0.02$ \\
\hline $\mathrm{MSTM}+\mathrm{P}_{\mathrm{RT}}$ & $80.0 \pm 0.2$ & $12.2 \pm 0.02$ & $0.5 \pm 0.05$ & $3.0 \pm 0.3$ & $4.4 \pm 0.02$ \\
\hline MSTMRef.T & $82.0 \pm 0.2$ & $10.3 \pm 0.1$ & $0.5 \pm 0.05$ & $2.8 \pm 0.2$ & $4.3 \pm 0.01$ \\
\hline MSTMRT & $86.3 \pm 0.3^{*}$ & $3.3 \pm 0.2$ & $0.5 \pm 0.1$ & $3.4 \pm 0.2$ & $6.5 \pm 0.02$ \\
\hline PTM + Pref.T & $79.0 \pm 0.2$ & $5.3 \pm 0.2$ & $0.5 \pm 0.06$ & $4.2 \pm 0.1$ & $10.9 \pm 0.03$ \\
\hline $\mathrm{PTM}+\mathrm{P}_{\mathrm{RT}}$ & $80.0 \pm 0.1$ & $6.8 \pm 0.2$ & $0.5 \pm 0.05$ & $3.8 \pm 0.2$ & $8.8 \pm 0.03$ \\
\hline PTMRef.T & $79.0 \pm 0.2$ & $9.4 \pm 0.02$ & $0.5 \pm 0.1$ & $4.5 \pm 0.2^{*}$ & $6.5 \pm 0.01$ \\
\hline PTMRT & $77.0 \pm 0.3$ & $10.8 \pm 0.3$ & $0.5 \pm 0.06$ & $4.0 \pm 0.3$ & $7.6 \pm 0.02$ \\
\hline
\end{tabular}

177 Values are means \pm SD of triplicate determinations.

178 Values in same columns bearing the superscript $\left(^{*}\right)$ are significant at $\mathrm{P}<0.05$

179

180

181 
183 Table 5. Proximate composition of tigernut milk products obtained from various processing 184 treatments after twenty (20) days of production.

\begin{tabular}{|c|c|c|c|c|c|}
\hline Treatment Sample & Moisture & Carbohydrate & Ash & Fat & Protein \\
\hline & $(\%)$ & $(\%)$ & $(\%)$ & $(\%)$ & $(\%)$ \\
\hline WSTM + PRef.T & $75.0 \pm 0.2$ & $14.2 \pm 0.1$ & $0.5 \pm 0.1$ & $3.7 \pm 0.2$ & $6.5 \pm 0.02$ \\
\hline WSTM + PRT & $83.0 \pm 0.3^{*}$ & $3.2 \pm 0.03$ & $0.5 \pm 0.1$ & $4.5 \pm 0.3^{*}$ & $8.8 \pm 0.02$ \\
\hline WSTMRef.T & $80.0 \pm 0.3$ & $8.9 \pm 0.2$ & $0.5 \pm 0.05$ & $4.0 \pm 0.2$ & $6.5 \pm 0.03$ \\
\hline WSTMRT & $83.0 \pm 0.2^{*}$ & $7.5 \pm 0.2$ & $0.5 \pm 0.1$ & $3.5 \pm 0.1$ & $5.5 \pm 0.03$ \\
\hline TTM + Pref.T & $78.0 \pm 0.2$ & $13.0 \pm 0.3$ & $0.4 \pm 0.06$ & $3.0 \pm 0.2$ & $5.5 \pm 0.02$ \\
\hline $\mathrm{TTM}+\mathrm{P}_{\mathrm{RT}}$ & $83.0 \pm 0.2^{*}$ & $6.4 \pm 0.2$ & $0.5 \pm 0.2$ & $3.5 \pm 0.2$ & $6.5 \pm 0.01$ \\
\hline TTMRef.T & $76.0 \pm 0.2$ & $14.6 \pm 0.3$ & $0.5 \pm 0.06$ & $3.5 \pm 0.02$ & $4.4 \pm 0.03$ \\
\hline TTMRT & $83.0 \pm 0.2^{*}$ & $9.1 \pm 0.2$ & $0.5 \pm 0.05$ & $4.0 \pm 0.3$ & $3.3 \pm 0.02$ \\
\hline MSTM + PRef.T & $79.0 \pm 0.3$ & $12.2 \pm 0.2$ & $0.5 \pm 0.2$ & $2.7 \pm 0.2$ & $5.7 \pm 0.02$ \\
\hline $\mathrm{MSTM}+\mathrm{P}_{\mathrm{RT}}$ & $78.0 \pm 0.2$ & $13.3 \pm 0.4$ & $0.4 \pm 0.1$ & $3.8 \pm 0.2$ & $4.3 \pm 0.01$ \\
\hline MSTMRef.T & $78.0 \pm 0.3$ & $12.0 \pm 0.03$ & $0.5 \pm 0.05$ & $3.0 \pm 0.2$ & $6.5 \pm 0.02$ \\
\hline MSTMRT & $80.0 \pm 0.3$ & $7.0 \pm 0.02$ & $0.5 \pm 0.06$ & $3.4 \pm 0.1$ & $8.7 \pm 0.03$ \\
\hline PTM + PRef.T & $80.0 \pm 0.3$ & $8.9 \pm 0.2$ & $0.5 \pm 0.2$ & $4.0 \pm 0.2$ & $6.5 \pm 0.02$ \\
\hline $\mathrm{PTM}+\mathrm{P}_{\mathrm{RT}}$ & $79.0 \pm 0.2$ & $8.3 \pm 0.1$ & $0.5 \pm 0.2$ & $4.5 \pm 0.2^{*}$ & $7.6 \pm 0.02$ \\
\hline PTMRef.T & $77.0 \pm 0.1$ & $12.7 \pm 0.2$ & $0.5 \pm 0.1$ & $4.2 \pm 0.3$ & $5.5 \pm 0.01$ \\
\hline PTMRT & $81.0 \pm 0.2$ & $6.0 \pm 0.2$ & $0.4 \pm 0.05$ & $3.8 \pm 0.06$ & $8.8 \pm 0.02$ \\
\hline
\end{tabular}

185 Values are means \pm SD of triplicate determinations.

186 Values in same columns bearing the superscript $\left(^{*}\right)$ are significant at $\mathrm{P}<0.05$

\section{Discussion}

It was observed that all samples had high moisture content, with the samples stored at room temperature having the highest percentage of moisture. This could affect the stability and safety of

191 the various beverage samples with respect to microbial growth and proliferation; as high moisture content allows microbial growth [19]. Total ash content in the various treatments was lower than the ash content of $1.5 \%$ as reported by Ukwuru et al. [6]. The crude fat content of the various milk 
194

195

196

197

198

199

200

201

202

203

204

205

206

207

208

209

210

211

212

213

214

215

216

217

218

219

220

221

222

223

224

225

226

227

228

229

samples were within the range of $2.3-6.5 \%$ and were below the minimum of $8 \%$ standard for dairy milk [12,13]. According to Belewu and Abodurin [16], tigernut itself is rich in fat $(25.5 \%)$. This shows that there is a wide difference between fat in tigernut tubers and its milk.

The current study is in accordance with the result of a previous study by Adgidzi in 2010 [20] , where production of acceptable beverages were made from tiger nuts. The beverage products were found to contain a proximate composition of $1.89 \%$ protein, $0.92 \%$ fat, $0.16 \%$ ash, $0.24 \%$ crude fiber, $76.86 \%$ moisture and $15.96 \%$ carbohydrates.

In general, it was established that processing treatment of the various tigernut milk samples has effect on the chemical characteristics of the milk products. Processing treatments affected the characteristics of the various samples in different ways; soaking increased the protein and fat, but sometimes reduced the moisture and carbohydrate content. It also reduced soluble antinutrients (eg tannins and polyphenols) which can be eliminated with the discarded soaking water. Toasting on the other hand, aids flavour development, removes heat labile antinutrients and increased the protein and fat contents. The increase in protein and fat could be attributed to the concentration of the constituents during toasting brought about by loss of moisture and reduction/destruction of certain protease inhibitors and other anti-nutrients like phytic acid and tannins which form complexes with protein and make protein unavailable during hydrolysis. A similar increase in protein content has been reported for Terminalia catappa seeds toasted at a high temperature [21]. Soaking in methanol reduced the fat content in the tigernut milk samples, as the raw tigernut was defatted with methanol. Pasteurization of the tigernut milk mixture also aided in destroying pathogens likely to be present as well as most spoilage organisms in the mixture as it normally controls both health and spoilage hazards.

Addition of preservative during processing had a significant effect on the chemical characteristics of the tigernut milk samples. During storage, the samples which had no preservative and were stored at room temperature dropped significantly in quality after 2 days, whereas the preserved samples without pasteurization deteriorated significantly $(\mathrm{P}<0.05)$ in quality on the first week, while the preserved samples that received pasteurization were found to stay more than a week with fair quality. All samples fell below acceptable range at third week.

There is increased utilization of tiger nut (Cyperus esculentus) nowadays, which might be as a result of awareness on the composition of tiger nut especially the protein content which helps in body development and tissue repair [15].

\section{Conclusions}

Tigernut tubers can be processed into various tigernut milk products using different treatments. The chemical characteristics of the various beverage products were significantly affected by the different processing treatments. The preservative treated samples that received pasteurized treatment were found to stay more than a week with fair quality.

Author Contributions: H.A and A.S. conceived and designed the experiments; A.S. performed the experiments; A.S., M.A. and H.A. analyzed the data; M.A. contributed reagents/materials/analysis tools; A.S. wrote the paper."

Conflicts of Interest: The authors declare no conflict of interest. 


\section{References}

1. Obizoba, I.C.; Anyika, J.U. Nutritive value of baobab milk (Adansoniadigitata L), Hungary rice, Acha (Digitanaexillis) flours. Plant Foods for Hum. Nutr. 1995, 46: 156-165.

2. Singh, T.; Bains, G.S. Grain extract-milk beverage, processing and physico- chemical characteristics. J. Food Sci. 1988, 53: 1387-1390.

3. Obizoba, I.C.; Egbunna, H.I. Effect of germination on fermentation on the nutritional quality of bambara nut (Vagndzei subterranean Thourars) and its products (milk). Plant Foods for Hum. Nutr. 1992, 42: 13-23.

4. Odo, F.O. Consumer acceptance of groundnut milk. Proceedings of the 25 Annual Conference of the Nigerian Institute of Food Sci. and Tech. (NIFST). 2009, November 5-9, Lagos, Nigeria, pp: 135137.

5. Akubor, P.I. Physico-chemical and sensory characteristics of melon seed milk. J. Food Sci. Tech. 1998, 35: 93-95.

6. Ukwuru, M.U.; Omachona, L.J.; Onokah, N. Production and quality assessment of tigernut (Cyperus esculentus) imitation milk during storage. J. Food Sci. Technol. 2008, 45: 180-182.

7. Anderson, J.W.; Smith, B.M.; Gustatson, N.J. Health benefits and practical aspects of high fibre diets. Am. J. Clin. Nutr. 1994, 59: 12425-12475.

8. Temple, V.T.; Ojobe, T.O.; Kapu, M.M. Chemical analysis of Tigernut (Cyperus esculentus). Journal Science Food Agriculture. 1990, 50: 261- 263.

9. Temple, V.J. Lesser known plant foods. In: Nutritional quality of plant foods. Osagie AU and Eka OU (Eds). Post-harvest Research Unit, University of Benin, Nigeria. 1989 pp: 245-274.

10. Omode, A.; Fatoki, O.; Olaogun, K.A. Physico-chemial properties of some under- $\quad$ exploited and non-conventional oil seed. J. Agric. Food Chem. 1995, 11: 50-53.

11. Ojobe, T.O.; Tempo, V.J. Amino acid composition of tigernut tubers (Cyperus esculentus). Nig. J. Sci. Biotechnol.. 1983, 2: 35-38.

12. FAO/WHO. Milk and milk products. Joint FAO/WHO Food standards programme. Codex Alimentarius Commission. 2002a, Pp: 42.

13. FAO/WHO. Joint FAO/WHO Expert Report on diet, nutrition and the prevention of chronic diseases, cited in Food and Nutrition Bulletin. 2002b, 24: 255-256.

14. Bosch, L.; Alegria, A.; .Farri, R. RP-HPLC determination of tigernut and its amino acid contents. Food Sci. Technol. Inter. 2005, 11: 33-40.

15. Gambo, A.; Da'u, A. Tiger nut (cyperus esculentus): Composition, Products, Uses and health benefits A review. Bayero Journal of Pure and Applied Sciences. 2014, 7(1): $56-61$ 
267
16. Belewu, M.A.; Abodunrin, O.A. Preparation of Kunnu from unexploited rich food source: Tiger nut (Cyperus esculentus). World Journal of Diary and Food Sciences. 2006, 1: 19-21.

17. Adejuyitan, J.A. Tigernut processing: its food uses and health benefits. Am J Food Technol. 2011, 6(3):197-201.

18. Association of Official Analytical Chemists. Official methods of analysis. 17th Edn., Association of Official Analytical Chemists. 1995, Washington DC.

19. Sa'id, A.M.; Abubakar, H.; Bello, B. Sensory and microbiological analysis of Tigernut (cyperus esculentus) beverage. Pak. J. Nutr. 2017, 16: 731-737.

20. Adgidzi, E.A. Effect of processing methods on the yield and quality of aqueous extracts and yoghurtlike products from Tigernuts (Cyperus esculentus). MSc Thesis submitted to the Department of Food Science and Technology. University of Agriculture, Makurdi. Benue State. 2010, p. 73.

21. Ezeokonkwo, C.A. Effect of wasting nutrient composition of Terminalia Catappa L. seed. Nig. J. Nutr. Sci. 2005, 26 (1) : 19-24. 